\title{
Smart Device
}

National Cancer Institute

\section{Source}

National Cancer Institute. Smart Device. NCI Thesaurus. Code C153216.

An electronic device that is capable of connecting to a network and can make use of the network for more complex services. 